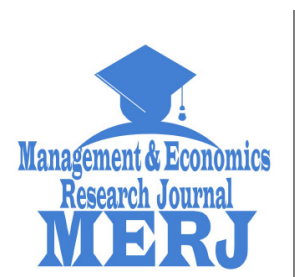

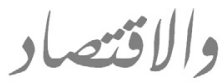

Management \& Economics Research Journal ISSN 2710-8856 (Online)

ISSN 2676-184X (Print)

Vol. 4 No. 1 (2022): March, pp. 128-152

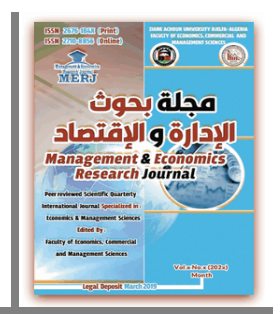

https://doi.org/10.48100/merj.2022.190

Check for updates

\title{
Impact of Psychopathy and Narcissism on Employees' Adverse Outcomes: A Perspective of Ethical Climate Theory and Threatened-Egotism Model
}

\section{Muhammad Salman Chughtai ${ }^{1}$ (D) Huma Akram ${ }^{2}$ D , Tabassum Razzaq ${ }^{3}$ D, Adeela Rasheed ${ }^{4}$, Rabia Shah ${ }^{5}$ (D)}

${ }^{1}$ Faculty of Management Sciences, International Islamic University, Islamabad (Pakistan)

$\triangle$ salman.phdmgt80@iiu.edu.pk

${ }^{2}$ School of Education, Northeast Normal University, Changchun (China)

$\triangle$ xium087@nenu.edu.cn

${ }^{3}$ Superior College of Law, Lahore (Pakistan)

$\triangle$ tabassum.razzaq.ca@gmail.com

${ }^{4}$ Department of Management Sciences, Riphah International University, Faisalabad Campus,

Faisalabad (Pakistan)

$\triangle$ adeelarasheed325@gmail.com

${ }^{5}$ Institute of Management Sciences, IMSciences, Peshawar (Pakistan)

$\square$ rabia.shah60@yahoo.com

Received: 28-01-2022

Accepted: 01-03-2022

Published online: 05-03-2022

\section{How to Cite:}

Chughtai, M. S., Akram, H., Razzaq, T., Rasheed, A., \& Shah, R. (2022). Impact of Psychopathy and Narcissism on Employees' Adverse Outcomes: A Perspective of Ethical Climate Theory and Threatened-Egotism Model. Management \& Economics Research Journal,4(1), 128-152. https://doi.org/10.48100/merj.2022.190

\section{Abstract:}

This study examines the impact of psychopathic and narcissistic personalities on employees' adverse outcomes. Additionally, this study investigates the intervening mechanism of workplace incivility among the

•Corresponding author: Faculty of Management Sciences, International Islamic University, Islamabad (Pakistan).

[ $\square$ salman.phdmgt80@iiu.edu.pk]

(C)2022 the Author(s). This is an open-access article distributed under the terms of (CC BY-NC 4.0) which permits use, distribution and reproduction in any medium, provided the original work is properly cited and is not used for commercial purposes. 
relationship between psychopathic and narcissistic personalities and adverse outcomes. Furthermore, the interactive impact of Islamic work values was also tested between the association of workplace incivility and adverse outcomes. Data was collected through a survey method from 404 permanent public sector employees using the purposive sampling technique in two different time lags. PROCESS-macro was used to test indirect, interactive, and moderated mediation effects. The findings of this study confirm the direct effect relationship between those psychopathic and narcissistic personalities and employees' adverse outcomes. Further, this study demonstrates that workplace incivility indirectly enhances adverse employee outcomes. Finally, the study findings revealed that a higher level of Islamic work values reduces the adverse outcomes of employees having psychopathic and narcissistic personality characteristics. We also tested the moderated mediation model, which disclosed that a higher level of Islamic work values reduces the negativity level of psychopathic personalities, further decreasing the level of counterproductive work behaviors via workplace incivility. However, there was no moderating role of Islamic work values in reducing narcissist personalities' negativity levels and counterproductive work behaviors via workplace incivility. The present study provides information to the management of public sector organizations on how they can overcome their workforce's negative behaviors and outcomes by implementing the Islamic ethical system. This attempt contributed to ethical climate theory and threatened the egotism model by explaining that negative personality traits predict uncivil behaviors, leading to adverse outcomes. This study further contributes that the organization's ethical climate helps the individuals overcome the negativity of their personalities and negative behaviors.

Keywords: Psychopathy (PY), Narcissism (NM), Workplace Incivility (WPI), Islamic Work Values (IWVs), Counterproductive Work Behaviors (CWBs), Ethical Climate Theory (ECT), Threatened-Egotism Model (TEM), Public Sector.

JEL Codes: M12, J24, O15, D23.

\section{Introduction}

Organizational and individual performance is influenced by individuals' personality characteristics and behaviors (De Dreu \& Nauta, 2009). Positive traits positively impact the work environment and society, resulting in harmony, cooperation, and patience (Harms \& Spain, 2015). Besides this, negative personality holders create a toxic atmosphere that is disadvantageous for society and organizations and disturbs the individuals' productivity and psychological and physical health (Hamesch, Cropley, \& 
Chughtai, M. S., Akram, H., Razzaq, T., Rasheed, A., \& Shah, R.

Lang, 2014; Jelavić, Aleksić, \& Braje, 2021). Earlier studies pointed out that public sector organizations face uncivil and harmful behaviors from their workforce at the workplace (Abid et al., 2015; Sguera et al., 2016). In the current era, public sector organizations are experiencing counterproductive work behaviors (CWBs) that contain sabotage, verbal abuse, and stealing (Bibi, Karim, \& ud Din, 2013; González-Navarro et al., 2018) and eventually harm the administrative setup.

Individuals' personality describes as nature and regulations through which they demonstrate their specific actions, which also becomes the cause of their aggression and CWBs at the workplace (Phipps, Prieto, \& Deis, 2015; Spector, 2011). Negative personalities such as narcissism and psychopathy are well-known as cold-hearted, egotistic, uncaring, and malicious in their interpersonal communications at the workplace (Miller et al., 2021; Paulhus $\&$ Williams, 2002). Scholars have realized that narcissism and psychopathy are associated with unscrupulous behaviors, which is an immoral practice in the workplace (Garcia \& Rosenberg, 2016; O'Boyle et al., 2012; Roeser et al., 2016). Narcissist traits are well-known for their self-promotion and attentionseeking behaviors, the charm of high self-esteem, dominance, and not liking criticism (Miller et al., 2021; Morf \& Rhodewalt, 2001; O'Boyle et al., 2012). Conversely, psychopathic individuals are well-known for their characteristics of irresponsible behavior, emotionally cold, lack of empathy for others, and being untrustworthy toward others (LeBreton, Shiverdecker, \& Grimaldi, 2018; Shagufta \& Nazir, 2021). Contemporary studies have found that noncooperative and unethical activities are linked with negative personality features, i.e., DT (Garcia \& Rosenberg, 2016; Roeser et al., 2016). In contrast, it has been found that psychopathic personalities feel satisfaction about their jobs with security, but these individuals lack fearlessness (Eisenbarth et al., 2022).

Scholars elucidated that unethical decision-making, hostile behavior, lack of responsiveness, immoral behavior, and adverse reactions with supervisors, juniors, or peers are a portion of CWBs (Cohen, 2016; Garcia \& Rosenberg, 2016; O'Boyle et al., 2012). Several research works have been conducted to determine the precursors of CWBs, and the findings of these studies asserted that narcissism and psychopathy cause harmful activities, i.e., CWBs (Özsoy, 2018; Stoica, 2021). Moreover, we focused on the factors that serve as mechanisms in the link between narcissism and psychopathy, and CWBs. Previous literature has shown that workplace incivility (WPI) is a significant predictor of adverse consequences, i.e., burnout, higher level of dissatisfaction and withdrawal, and CWBs (Liu et al., 2020b; Loh, Thorsteinsson, \& Loi, 2021; Murtaza, Roques, \& Khan, 2020; Penney \& 
Spector, 2005; Schilpzand, De Pater, \& Erez, 2016). A recent review of WPI focused on the undesirable consequences for organizations that are employee's negative behavior (Akella \& Lewis, 2019; Schilpzand, De Pater, $\&$ Erez, 2016), leading to financial and social costs (Porath \& Pearson, 2013), specifically when it alters into CWBs.

The current study stresses ethical work principles from an Islamic values viewpoint, as Islamic work values (IWVs) are centered on justice, trusteeship, ethics, kind-heartedness, benevolence, and confidence (Rice, 1999; Yousef, 2001). Scholars ordained that IWVs increase personalities' motivational levels (Nasution \& Rafiki, 2019) and decrease adverse consequences such as WPI (Ahmad, 2011; Wilson, 2012). IWVs encompass the individuals' way of living and society (Gheitani et al., 2019). IWVs stress leniency, self-sacrifice, fairness, and collaboration amongst humanity (Quoquab \& Mohammad, 2013), likely reducing the intensity of adverse activities such as WPI and CWBs. Additionally, it has been observed that IWVs enable individuals to produce positive and fruitful activities at the workplace, i.e., sharing of knowledge, work motivation, and optimistic response to the organizational change activities (Al-Shamali et al., 2021; Chaudhary et al., 2021; Yuliusdharma et al., 2022). Thus, we propose that IWVs buffer the harmful effects of WPI on employees' CWBs.

The present study finds out the answer to the following questions; by investigating the intervening mechanism of WPI between psychopathic, narcissist personalities and CWBs; also, this study find out the answer to the question about the role of Islamic work values by examining IWVs as a moderator between WPI - CWBs relationship. This study also answers the call for research by Eisenbarth et al. (2022), Lata and Chaudhry (2020), Shin and Hur (2019), and Liu et al. (2020a) by investigating the direct effect of psychopathic and narcissist personalities on CWBs. This is achieved by explaining the intervening mechanism of WPI by overcoming the gap, as Han et al. (2021) suggested, especially in the context of public sector organizations. We also answer the empirical research gap, as suggested by Cortina et al. (2021), by examining the moderating role of Islamic work values and how these values as the organization's culture reduce the positive intensity of the affiliation amongst WPI and CWBs. The present study extends the knowledge about personality psychology and works ethics by applying ethical climate theory and the threatened-egotism model. 
Chughtai, M. S., Akram, H., Razzaq, T., Rasheed, A., \& Shah, R.

\section{Theoretical underpinning and hypothesis development}

The Threatened-egotism model (TEM) (Bushman \& Baumeister, 1998 ) is advocated owing to the higher observation of general societal fear of the ego of characteristic dark individuals such as narcissists and psychopathics (Hart, Tortoriello, \& Richardson, 2021; Konrath, Bushman, \& Campbell, 2006) and low self-confidence (Bushman \& Baumeister, 1998). These personalities act violently and disrespectfully in the working environment to maintain their profound impact on self-confidence (Stenason, 2014) facing others at the workplace. Low self-esteem and fear of threat to the ego of dark personalities (psychopathic and narcissist) increase negative emotions and expressions, i.e., aggression, humiliation, and anger (Costello \& Dunaway, 2003), leading to negative behavior, i.e., CWBs (Brender-Ilan \& Sheaffer, 2019; Hart, Adams, \& Tortoriello, 2017). Additionally, the threatened-egotism model (Bushman \& Baumeister, 1998) explains that low morale and high perceptions of dark personalities, such as narcissism and psychopathic, provide them with insecure feelings that hurt their ego and become the causes of aggressive behaviors.

Further, when encountering such situations, their behavior turns uncivil, especially when they are in authoritative positions at the workplace (Bushman \& Baumeister, 1998). This situation leads to uncivil behavior of these dark characteristics, i.e., narcissists and psychopathic individuals, resulting in adverse outcomes such as CWBs. The organization's ethical climate is derived from the organization's ethical culture, which is formed through ethical norms and identity (Cullen, Victor, \& Bronson, 1993). Ethical climate perceptions of the employees increase several positive outcomes, i.e., organizational commitment, psychological well-being, and job satisfaction, and decrease dysfunctional behaviors (Martin \& Cullen, 2006). Studies have shown that the organization's work ethics negatively affect CWBs (Hayati, Yuningsih, \& Caniago, 2018). The ethical atmosphere is meticulously connected with employees' encouraging activities (Wang \& Hsieh, 2013) that elasticities awareness about impartial communications and proper management of official activities (Victor \& Cullen, 1987, 1988) through effective decision-making. Using the theoretical lens of ECT (Victor \& Cullen, 1987, 1988), the present study examines the mechanism of moderation of IWVs and how injurious effects of WPI on CWBs are mitigated. 


\subsection{Psychopathy, narcissism, and employees' adverse outcomes}

Individuals with the personality traits of narcissism and psychopathy mostly avoid doing teamwork tasks, which ultimately decreases their productivity as they are difficult to mingle with their colleagues (Anninos, 2018). Psychopathy is a dark personality characterized as a character trait, including self-centered and deceiving social and professional communication, lack of emotion and understanding, and thoughtless and undeveloped behavior style (Boey \& Vantilborgh, 2016). Psychopathy is considered low sensitivity, understanding, impulsivity, and a lack of responsibility or sorrow (Cohen, 2016; Paulhus \& Williams, 2002), producing selfishness, egoism, and untrustworthy social relations in society or at the workplace (Jakobwitz \& Egan, 2006). It has been observed that the low positive self-esteem of psychopathic personalities influences them to demonstrate anti-social and egoistical activities in the workplace (Shagufta \& Nazir, 2021). Likewise, narcissism is another part of the dark personality and is associated with the wisdom of perceived authority, supremacy, and dominating behavior (Jonason, Wee, \& Li, 2015; Paulhus \& Williams, 2002). Individuals with this personality are usually pretentious, attention seekers, and admire self-praise (Jakobwitz \& Egan, 2006). Narcissistic individuals are susceptible to criticizing others, attempting to make a lasting impression on others, and indulging in aggression, egoistical and terrible behavior (Chughtai et al., 2020; Paulhus \& Williams, 2002; Vize et al., 2021).

Counterproductive work behaviors (CWBs) entail two types of behaviors that occur within the organization (theft of any material) or conflict between employees (the use of promiscuous conversations and abuse) (Viswesvaran, Deshpande, \& Milman, 1998). CWBs usually comprise cyberloafing, absenteeism, and low efficiency (Hauge, Skogstad, \& Einarsen, 2009). CWBs are voluntary or deliberate behavior that can cause direct or indirect damage to the organization or harm the workforce's well-being (McShane \& Von Glinow, 2013). According to scholars, CWBs are volitional acts that harm or assume damage relations and their associates, e.g., clients, agents, consumers, and managers (Debusscher, Hofmans, \& De Fruyt, 2016). Several meta-analytic studies and reviews showed that dark personalities are positively associated with undesirable outcomes at the workplace, i.e., CWBs, abusive supervision, dishonorable behavior, immorality, unprofessional manners, and work-related stress (Greenbaum et al., 2017; Grijalva \& Newman, 2015). The public sector's workplace environment, specifically in developing countries, is jeopardized by low self-esteemed dark personal characteristics, increasing destructive thoughts and behaviors, such as WPI, 
Chughtai, M. S., Akram, H., Razzaq, T., Rasheed, A., \& Shah, R.

CWBs, and aggression. (Brender-Ilan \& Sheaffer, 2019; Costello \& Dunaway, 2003; Hart, Adams, \& Tortoriello, 2017). Thus, we hypothesize that:

$\mathbf{H}_{1 \mathbf{a}}$ : Narcissism is positively linked to employees' adverse outcomes.

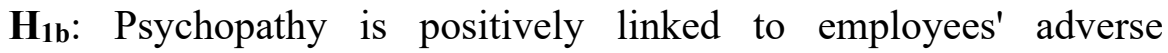
outcomes.

\subsection{Workplace Incivility (WPI) as a mediator}

Incivility of individuals in the workplace includes every act considered professionally immoral, misconduct, or uncivil (Andersson \& Pearson, 1999). On the other hand, if we talk about incivility in the workplace includes violation of organizational rules and policies and negative behaviors with peers and subordinates in the form of rudeness (Cortina, Sandy Hershcovis, \& Clancy, 2021). Additionally, Porath and Pearson (2009) provide the main features of workplace incivility, such as violation of norms, vague intent, and low intensity connected with uncivil behaviors. Moreover, several studies endorsed an optimistic association between WPI and CWBs (Penney \& Spector, 2005; Schilpzand, De Pater, \& Erez, 2016). Additionally, research has found several findings that employees who demonstrate uncivil behaviors at the workplace suffer from different negative consequences such as distress, substance abuse, dissatisfaction, counterproductive work behaviors, decrease in commitment and creativity as well (Cortina et al., 2017; Cortina, Sandy Hershcovis \& Clancy, 2021; Loh, Thorsteinsson, \& Loi, 2021; Schilpzand, De Pater, \& Erez, 2016). Scholars expounded that WPI affects the individuals involved in unethical practices and those who experience discourteous behaviors, which obstruct the overall organization (He et al., 2021; Lim, Cortina, \& Magley, 2008) and creates a toxic climate (Andersson \& Pearson, 1999). Previous research exposed that WPI produces objectionable integrities that disturb physical, mental, professional, and spiritual health (Lim \& Cortina, 2005). This ultimately leads to decreased job satisfaction, commitment, and the OCB and increased job and psychological stress (Chen \& Wang, 2019; Cortina et al., 2001; Pearson \& Porath, 2005; Porath \& Pearson, 2013). Thus, we hypothesize that:

$\mathbf{H}_{2 \mathbf{a}}$ : Workplace incivility mediates the positive association between narcissism and employees' adverse outcomes.

$\mathbf{H}_{2 \mathbf{b}}$ : Workplace incivility mediates the positive association between psychopathy and employees' adverse outcomes. 


\subsection{Islamic work values (IWVs) as a moderator}

IWVs have their foundation in the Holy Quran and the lessons, principles, and teachings of the Holy Prophet MUHAMMAD (SAW). It is also derived from the traditions established by the first-four Islamic Caliphs (Rizk, 2008). Work values defined by Islam are restricted to his followers and universal to everyone's daily life (Abbasi, Rehman, \& Bibi, 2011). Discipline and quality of work in an organization depend upon the organization's working environment influenced by the ethical norms of employees and management (Kozako et al., 2018). Moreover, Islamic work values (IWVs) are predecessors and standards for individuals' intrinsic motivation (Gheitani et al., 2019). These Islamic values further enhance positive behaviors, i.e., performance and OCB, and reduce harmful activities such as egoistic and uncivil behaviors at the workplace (Abbasi, 2015; Chughtai \& Ali Shah, 2020; Suryanto, 2016). IWVs are based on Islamic ethics that emphasizes cooperation, teamwork, and unity (Yousef, 2001), especially in the workplace, because Islamic teachings rely on a virtuous way of handling things (Murtaza et al., 2016). Moreover, Hayati et al. (2018) stated in their study that employees high on IWV could control and manage the possible stressors and pressures on the job, ultimately reducing the CWBs. Additionally, an ethical climate reduces emotional exhaustion (Yang, Tsai, \& Tsai, 2014), anger, aggression, fatigue (Chen, Chen, \& Liu, 2013), and knowledge-hiding behaviors (Islam et al., 2021). Scholars elaborated that IWVs enhance employee morale, reducing CWBs (Pagliaro et al., 2018). Literature on Islamic work values evidenced that IWVs moderate the relationship of different variable associations in different organizational backgrounds (Ahmed et al., 2019; Javaid et al., 2018; Kareem \& bin Azmin, 2018; Qayyum et al., 2018). Thus, we hypothesize that:

$\mathbf{H}_{3}$ : Islamic work values moderate the positive relationship between workplace incivility and employees' adverse outcomes; in the sense that a higher level of Islamic work values will weaken the positive relationship.

\subsection{Moderated mediation}

In sum, we propose a moderated mediation model for CWBs: narcissism and psychopathy are related to CWBs via WPI. Our model suggests that dark personalities, narcissism, and psychopathy form uncivil behaviors as they feel a hazard to their self-respect that further translates into adverse outcomes such as CWBs. In contrast, individuals' level of ethics in the form of IWVs influences the relationship between WPI and CWBs. To 
Chughtai, M. S., Akram, H., Razzaq, T., Rasheed, A., \& Shah, R.

achieve this purpose, we operationalize the moderation mediation analysis by adopting model-14 as suggested by Hayes $(2015,2018)$, through which we thoroughly analyze the conditional indirect effect of IWVs amongst the indirect relationship of dark personalities narcissism and psychopathy and CWBs via WPI, so we hypothesize that:

$\mathbf{H}_{4 \mathrm{a}}$ : Islamic Work Values will moderate the positive indirect effect of narcissism on employees' adverse outcomes through workplace incivility in the sense that a higher level of Islamic work values will weaken the positive indirect effect.

$\mathbf{H}_{4 \mathrm{~b}}$ : Islamic work values will moderate the positive indirect effect of psychopathy on employees' adverse outcomes through workplace incivility in the sense that a higher level of Islamic work values will weaken the positive indirect effect.

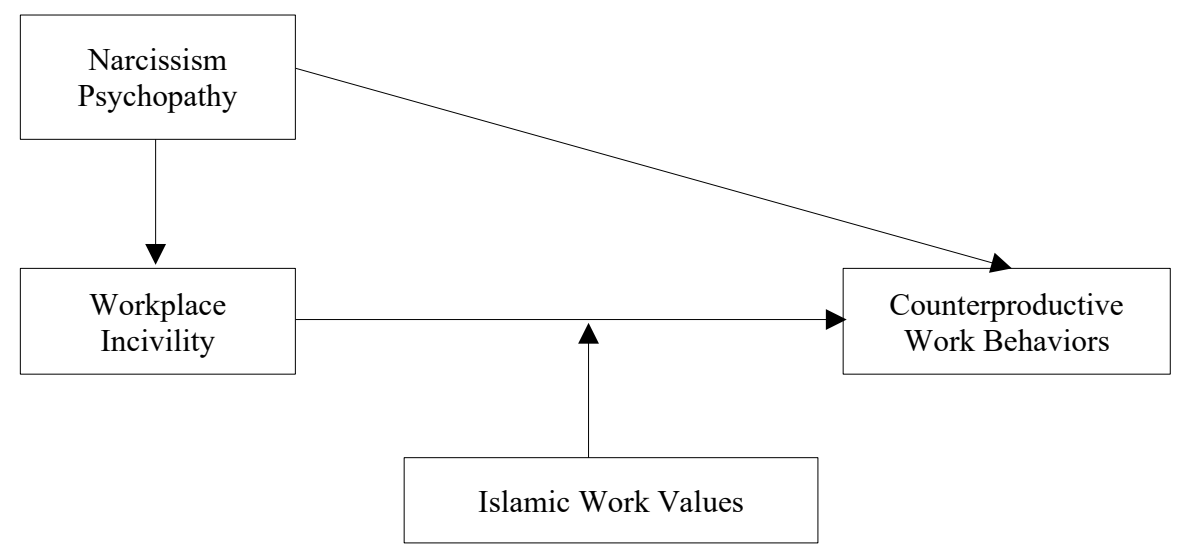

Figure 1. Conceptual model

\section{Research design}

\subsection{Sampling and data collection procedure}

Data for the present study was collected from the permanent ministerial staff of a public sector organization through a self-administered data collection technique. The motive for selecting this sample from public sector organizations is that management and policymakers of public sector institutions, especially in developing countries, are worried about the uncivil CWBs at the workplace that resulted in their institutional deficiency (Haque, 
2002; Vickers, 2006). Through the purposive sampling technique, data was collected because this technique helps the researcher collect information from the sample and population effectively according to the research objectives. Through this technique, research scholars found those individuals who hold the information related to the study and voluntarily and willingly participate and share their opinions and experience (Bernard, 2017; Etikan, Musa, \& Alkassim, 2016).

Data for this study were collected in two temporal time intervals; in the first interval, questionnaires were distributed for narcissism, psychopathy, and WPI. In the second interval, questionnaires were distributed CWBs and IWVs. In the first-time lag, 650 questionnaires were distributed to ministerial employees of public sector organizations in Lahore, Rawalpindi Multan, and Bahawalpur (major cities of Punjab, Pakistan). At the end of the first interval, 550 questionnaires were received; in the second lag, questionnaires were distributed to those ministerial employees who participated in the first-time lag; finally, 404 questionnaires were found correct for further statistical analysis, so the response rate of the present study was $62.15 \%$. Common method variance of the data was tested through Herman's (1967) single-factor analysis, and the cumulative percentage value was $21.62 \%$ which is less than the threshold of $50 \%$ for the normality of data.

\subsection{Measurement tools}

All variables of the present study were measured on 5 points Likert scale. CWBs were measured using the Likert scale of (Never-1 to Everyday5). On the other hand, psychopathy, narcissism, workplace incivility, and Islamic work values were measured using the Likert scale of (Strongly Disagree-1 to Strongly Agree-5).

- Psychopathy and narcissism: were measured through an 18-item scale from Jones \& Paulhus (2014). The study participants were asked to express how frequently they engage in these behaviors as narrated in questions.

- Counterproductive work behaviors: (sabotage, theft, withdrawal, abuse, and production deviance) were measured using 31 items from Spector et al. (2006). The study's participants were requested to give their views about the behaviors they were engaged in for the last year.

- Workplace incivility: was analyzed using a 7-item scale from Cortina et al. (2001). The study's participants were enquired to give their views about the behaviors they were engaged in for the last year.

- Islamic work values: having a 24-items (Cooperation, Forgiveness, 
Chughtai, M. S., Akram, H., Razzaq, T., Rasheed, A., \& Shah, R.
Impact of Psychopathy and Narcissism on Employees' Adverse Outcomes: A Perspective of Ethical Climate Theory and Threatened-Egotism Model

Self-Discipline, and Patience) scale adopted from Wahab et al. (2016). The study's participants were asked to give their opinion about the behaviors they were engaged in for the last year.

\section{Results}

Table 1 shows the demographic information of the present study.

Table 1. Demographics

\begin{tabular}{llll}
\hline Category & & Frequency & Percentage \\
\hline Gender & Male & 356 & $88.1 \%$ \\
Age & Female & 48 & $11.9 \%$ \\
& $20-30$ (years) & 171 & $42.3 \%$ \\
& $31-40$ (years) & 161 & $39.9 \%$ \\
Education & $41-50$ (years) & 54 & $13.4 \%$ \\
& $51-60$ (years) & 18 & $4.5 \%$ \\
& Matriculation & 27 & $6.7 \%$ \\
Experience & Intermediate & 142 & $35.14 \%$ \\
& Graduation & 106 & $26.2 \%$ \\
& Masters & 98 & $24.2 \%$ \\
& MS/M.Phil & 31 & $7.7 \%$ \\
& Less than one (year) & 96 & $23.8 \%$ \\
& $1-5$ (years) & 93 & $23.0 \%$ \\
& 6-10 (years) & 70 & $17.3 \%$ \\
& $11-15$ (years) & 52 & $12.9 \%$ \\
& $16-20$ (years) & 42 & $10.4 \%$ \\
& More than 20 (years) & 51 & $12.6 \%$ \\
\hline
\end{tabular}

Table 2 depicts the correlational values descriptive and reliability statistics of the study. According to the values as given in the above table, all variables significantly correlated at the significance level of 0.01 , instead of two relationships that were significant at the level of 0.05 (NM positively interrelated with WPI where $\mathrm{r}=0.174^{*}, \mathrm{p}<0.05$, and positively interrelated with employees' adverse outcomes (CWBs) where $r=0.132^{*}, p<0.05$ ).

Table 2. Descriptive statistics, correlations, and reliability

\begin{tabular}{|c|c|c|c|c|c|c|c|c|}
\hline \multicolumn{2}{|c|}{ Variables } & Mean & SD & 1 & 2 & 4 & 5 & 6 \\
\hline 1 & NM & 3.02 & 0.5728 & $(0.770)$ & $0.253^{* *}$ & $0.174^{*}$ & $-0.135^{* *}$ & $0.132 *$ \\
\hline 2 & PY & 2.78 & 0.6541 & & $(0.750)$ & $0.302 * *$ & $-0.252 * *$ & $0.360 * *$ \\
\hline 4 & WPI & 1.94 & 0.7459 & & & $(0.840)$ & $-0.338 * *$ & $0.225^{* *}$ \\
\hline 5 & IWVs & 4.28 & 0.5407 & & & & $(0.890)$ & $-0.304 * *$ \\
\hline 6 & CWBs & 1.55 & 0.6432 & & & & & $(0.940)$ \\
\hline
\end{tabular}

NM; narcissism, PY; psychopathy, IWVs, Islamic work values, WPI, workplace incivility, CWBs, counterproductive work behaviors, ${ }^{*} \mathrm{p}<0.05 ;{ }^{* *} \mathrm{p}<0.01$; reliability statistics are in parenthesis. 
Table 3 shows the hierarchal regression values of the present study; according to the values, narcissism positively and significantly influences employees' adverse outcomes (CWBs) where $(\beta=0.24, \mathrm{p}<0.001)$, which proves $\mathrm{H}_{1 \mathrm{a}}$ of this study. Psychopathy positively and significantly influences employees' adverse outcomes (CWBs) where $(\beta=0.35, \mathrm{p}<0.001)$, proving $\mathrm{H} 1 \mathrm{~b}$ of this study.

Table 3. Unstandardized direct path coefficients

\begin{tabular}{lllllll}
\hline & $\beta$ & $\mathrm{SE}$ & $\mathrm{t}$-value & $\mathrm{R}^{2}$ & Adjusted $\mathrm{R}^{2}$ & $\mathrm{~F}$ \\
\hline $\mathrm{NM} \rightarrow$ CWBs & $0.24^{* *}$ & 0.07 & 4.515 & 0.113 & 0.110 & $27.615^{* * *}$ \\
$\mathrm{PY} \rightarrow$ CWBs & $0.35^{* * *}$ & 0.06 & 6.286 & 0.129 & 0.126 & $39.516^{* * *}$ \\
$\mathrm{WPI} \rightarrow$ CWBs & $0.19^{* * *}$ & 0.05 & 3.774 & 0.051 & 0.047 & $14.243^{* * *}$ \\
\hline
\end{tabular}

NM; narcissism, PY; psychopathy, IWVs, Islamic work values, WPI, workplace incivility, CWBs, counterproductive work behaviors, $\mathrm{N}=404{ }^{*} \mathrm{p}<0.05 ;{ }^{* *} \mathrm{p}<.0 .01 ; * * * \mathrm{p}<0.001$, unstandardized beta is reported here.

The test of indirect effect was analyzed using the bootstrapping method, as suggested by Hayes $(2015,2018)$, with a sample size of 5000 . According to the values as narrated in Table 4, WPI indirectly influences the relationship between NM and employees' adverse outcomes (CWBs), where $(\beta=0.02, \mathrm{LL} / \mathrm{UL}=0.01 / 0.06)$, WPI indirectly influence the relationship between PY and CWBs, where $(\beta=0.04, \mathrm{LL} / \mathrm{UL}=0.01 / 0.11)$, as zero was excluded in upper and low CIs values. Thus, these results prove our $\mathrm{H}_{2 \mathrm{a}}, \mathrm{H}_{2 \mathrm{~b}}$, and $\mathrm{H}_{2}$.

Table 4. Mediation analysis

\begin{tabular}{lccc}
\hline Model & $\begin{array}{c}\text { Total effect } \\
(\text { LL/UL) }\end{array}$ & $\begin{array}{c}\text { Direct effect } \\
(\mathrm{LL} / \mathrm{UL})\end{array}$ & $\begin{array}{c}\text { Indirect effect } \\
(\mathrm{LL} / \mathrm{UL})\end{array}$ \\
\hline $\mathrm{NM} \rightarrow \mathrm{WPI} \rightarrow$ CWBs & $0.04[0.21 / 0.14]$ & $0.05[0.23 / 0.12]$ & $0.02[0.01 / 0.06]$ \\
$\mathrm{PY} \rightarrow \mathrm{WPI} \rightarrow \mathrm{CWBs}$ & $0.35[0.19 / 0.52]$ & $0.32[0.12 / 0.51]$ & $0.04[0.01 / 0.11]$ \\
\hline
\end{tabular}

NM; narcissism, PY; psychopathy, IWVs, Islamic work values; WPI, workplace incivility; CWBs, counterproductive work behaviors; LL \& UL CI, lower- and upper-class interval.

Table 5 shows the values of the moderation analysis, which $(\beta=-$ $0.397, \mathrm{p}<0.001)$ depict that a higher level of IWVs reduces the optimistic intensity between WPI and employees' adverse outcomes (CWBs), which further explains that the higher presence of IWVs enforces the individuals to behave less uncivil which leads to decrease in employees' adverse outcomes (CWBs). Thus, these findings support $\mathrm{H}_{3}$.

Moderation values were plotted for moderation interaction slope, with low/high (Mean and SD). The moderation slope in Figure 2 represents a moderation effect of IWVs between WPI and employees' adverse outcomes (CWBs). The interaction graph further confirms that when individuals were at a higher level of WPI, their higher level of IWVs reduced their negative 
Chughtai, M. S., Akram, H., Razzaq, T., Rasheed, A., \& Shah, R.
Impact of Psychopathy and Narcissism on Employees' Adverse Outcomes: A Perspective of Ethical Climate Theory and Threatened-Egotism Model

emotions, further decreasing the employees' adverse outcomes (CWBs).

Table 5. Interaction analysis

\begin{tabular}{|c|c|c|c|}
\hline \multirow{2}{*}{ Variable } & \multicolumn{3}{|c|}{ Counterproductive work behavior } \\
\hline & $\beta$ & SE & $\mathrm{t}$ \\
\hline \multicolumn{4}{|l|}{ Step-I } \\
\hline Intercept & $2.591 * * *$ & 0.200 & 7.966 \\
\hline Gender & -0.045 & 0.122 & -0.367 \\
\hline Age & 0.017 & 0.081 & 0.208 \\
\hline Experience & 0.010 & 0.040 & 0.237 \\
\hline \multicolumn{4}{|l|}{ Step-II } \\
\hline Workplace incivility & $0.159 * *$ & 0.053 & 2.966 \\
\hline Islamic work values & $-0.171^{*}$ & 0.078 & -2.199 \\
\hline \multicolumn{4}{|l|}{ Step-III } \\
\hline $\begin{array}{l}\text { Workplace incivility x Islamic work } \\
\text { Values }\end{array}$ & $-0.397 * * *$ & 0.083 & -4.813 \\
\hline $\mathrm{R}^{2}$ & 0.184 & & \\
\hline Adjusted $\mathrm{R}^{2}$ & 0.162 & & \\
\hline $\mathrm{F}$ & $8.381 * * *$ & & \\
\hline
\end{tabular}

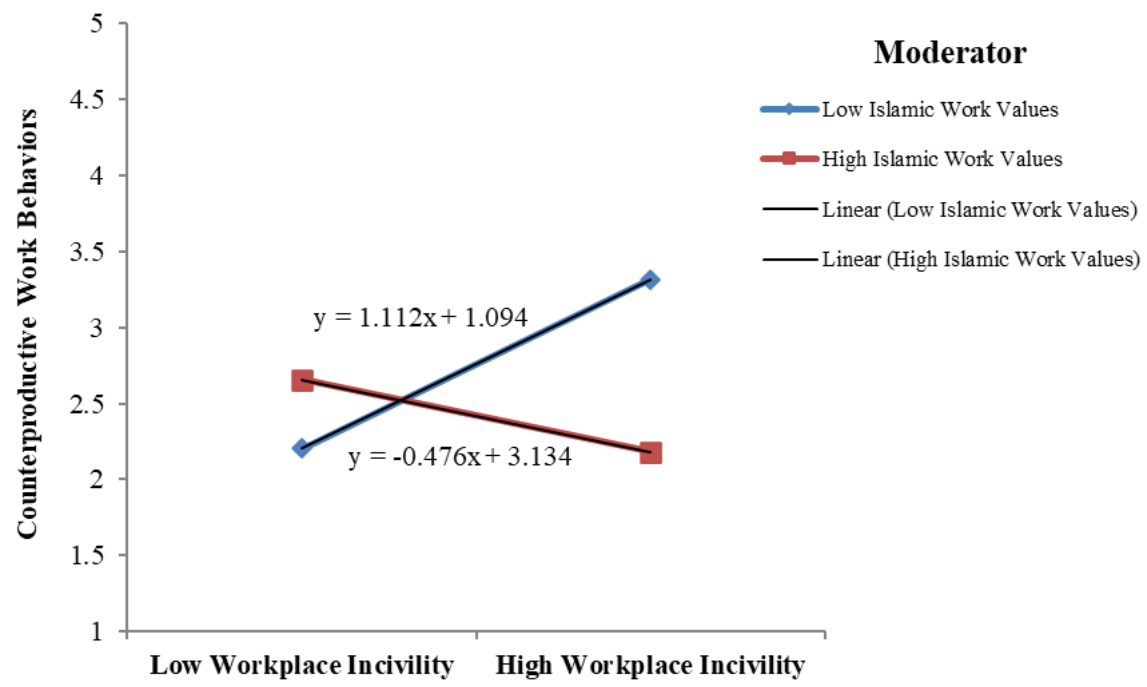

Figure 2. Moderation interaction graph

A detailed examination of the conditional indirect effect was analyzed using model-14 with a bootstrap sample size of 5000, as suggested by Hayes 
$(2015,2018)$. The conditional indirect effect of narcissism and psychopathy on employees' adverse outcomes (CWBs) through WPI at the values of IWVs was analyzed when the score of IWVs was the sample mean and the \pm SD (see Table 6). It was revealed that both high and low conditional indirect effects for narcissism were not significant, as zero was found among CIs values. Moreover, index values for narcissism were also found insignificant (index $=-0.04, \mathrm{LL} / \mathrm{UL}=-0.13 / 0.01$ ), which shows no such indirect influence of narcissism on employees' adverse outcomes (CWBs) through WPI when individuals were on a high and low level of IWVs. Thus, it disproves our $\mathrm{H}_{4 \mathrm{a}}$.

Moreover, it was revealed that the low and high conditional indirect effects for psychopathy were significant, as no zero was found among CIs values. Moreover, index values for psychopathy were found significant where (index $=-0.12$, LL / UL $=-0.23 /-0.05$ ), which shows the indirect influence of psychopathy on employees' adverse outcomes (CWBs) through WPI when individuals were on the low level of IWVs. Thus, it proves $\mathrm{H}_{4 b}$ of this study.

Table 6. Moderated mediation

\begin{tabular}{|c|c|c|c|c|}
\hline $\begin{array}{l}\text { NM (X-variable), } \\
\text { WPI (M-variable), } \\
\text { CWBs (Y-variable) }\end{array}$ & $\begin{array}{l}\text { Moderator } \\
\text { (IWVs) }\end{array}$ & CDI & SE & $\begin{array}{l}\text { Boot } \\
\text { LL \& UL CI }\end{array}$ \\
\hline At bellow than mean & Low $(-0.54)$ & 0.04 & 0.04 & $-0.01 / 0.11$ \\
\hline At above than mean & High $(0.54)$ & -0.01 & 0.01 & $-0.04 / 0.00$ \\
\hline At bellow than mean & Low $(-0.54)$ & 0.10 & 0.04 & $0.03 / 0.19$ \\
\hline At above than mean & High $(0.54)$ & -0.03 & 0.03 & $-0.10 /-0.01$ \\
\hline \multicolumn{5}{|c|}{ Moderated mediation index } \\
\hline \multicolumn{2}{|c|}{ WPI (M-variable), IWVs (W-variable) } & Index & Boot SE & Boot LL \& UL CI \\
\hline \multicolumn{2}{|c|}{$\begin{array}{l}\text { Narcissism (X-variable), } \\
\text { CWBs (Y-variable) }\end{array}$} & -0.04 & 0.03 & $-0.13 / 0.01$ \\
\hline \multicolumn{2}{|c|}{$\begin{array}{l}\text { Psychopathy (X-variable), } \\
\text { CWBs (Y-variable) }\end{array}$} & -0.12 & 0.04 & $-0.23 /-0.05$ \\
\hline
\end{tabular}

NM; narcissism, PY; psychopathy, IWVs; Islamic work values, WPI; workplace incivility, CWBs; counterproductive work behaviors, LL \& UL CI; lower- and upper-class interval.

\section{Discussion}

The present study's findings reveal that negative personalities, i.e., psychopathy and narcissism, are positively related to employees' adverse outcomes (CWBs). In other words, psychopathic and narcissistic individuals produce adverse outcomes (i.e., CWBs). This study's findings for hypotheses $\mathrm{H}_{1 \mathrm{a}}$ and $\mathrm{H}_{1 \mathrm{~b}}$ are consistent with the earlier studies (Cohen, 2016; Grijalva \& Newman, 2015; O'Boyle et al., 2012). Consequently, dark-personality-holder individuals observe that their ego is endangered (Bushman \& Baumeister, 1998). Due to low self-esteem, these personalities feel ostracized by their 
Chughtai, M. S., Akram, H., Razzaq, T., Rasheed, A., \& Shah, R.

peers' supervisors in the workplace (Grijalva \& Newman, 2015), demonstrating adverse outcomes. The second hypothesis predicted that WPI indirectly influences the relationship between negative personalities (psychopathic and narcissism) and employees' adverse outcomes (CWBs). The present study's findings support the acceptance of this hypothesis $\left(\mathrm{H}_{2}\right)$, which further explains that workplace incivility also becomes the cause of employees' adverse outcomes (CWBs) for the negative personality holders. The earlier studies also prove the study's findings, which reveal that WPI becomes the cause of adverse outcomes, i.e., CWBs (Karim et al., 2015). The third hypothesis of the present study hypothesized that IWVs moderate the relationship between WPI and employees' adverse outcomes (CWBs); the present study's findings also support the acceptance of this hypothesis $\left(\mathrm{H}_{3}\right)$. In other words, IWVs weaken the positive intensity between WPI and employees' adverse outcomes (CWBs), which means that a higher level of IWVs reduces incivility and decreases adverse outcomes, i.e., CWBs. Previous studies (Ahmed et al., 2019; Chughtai et al., 2020; Chughtai, 2017; Chughtai \& Ali Shah, 2020; Suib \& Said, 2017) also support the acceptance of this hypothesis by revealing that IWVs work as an ethical climate of the organization.

The findings showed that employees engaging in uncivil behavior results in adverse outcomes (CWBs). However, the workforce with higher IWVs shows less uncivil behavior and employees' adverse outcomes (CWBs). The final hypothesis of the present study predicted that IWVs moderate the indirect influence of psychopathy and narcissism on employees' adverse outcomes (CWBs) through WPI; the findings of this study provide support for the acceptance of $\mathrm{H}_{4 \mathrm{~b}}$, but no such significant support was found for the acceptance of $\mathrm{H}_{4 a}$. In other words, the indirect influence of psychopathy on employees' adverse outcomes (CWBs) through WPI was moderated when the individuals were on higher/lower levels of IWVs. In contrast, the indirect influence on employees' adverse outcomes (CWBs) through WPI was not moderated by the IWVs, which shows that higher and lower IWVs did not affect the indirect influence of narcissism on employees' adverse outcomes (CWBs) via WPI. This study's findings are also consistent with ECT (Victor \& Cullen, 1987, 1988), which states that the organization's climate, i.e., norms, traditions, and culture, affect individuals' personality, emotions, and behavior. 


\subsection{Theoretical and empirical contributions}

The present study adds knowledge to the literature on dark personalities (psychopathy and narcissism) by explaining the intervening influence of WPI that individuals' uncivil behavior at the workplace serves as a bridge between the negative personality of individuals and employees' adverse outcomes (CWBs). Secondly, in this study, IWVs are used as an ethical climate aspect of the organization formed through its norms and traditions. It works to reduce negative emotions and outcomes at the workplace. This study explains how IWVs influence the negative personalities (psychopathy and narcissism) at the workplace, reducing uncivil behaviors and harmful outcomes, i.e., employees' adverse outcomes (CWBs). As earlier scholars stated, incivility at the workplace leads to negative behavior, i.e., CWBs, psychological stress, and less job satisfaction (Cortina et al., 2001; Lim \& Cortina, 2005; Lim, Cortina, \& Magley, 2008). Present work also extends the knowledge of work ethics by infusing ECT (Victor \& Cullen, 1987, 1988) and explaining the moderating role of Islamic work values, reducing the egoistic nature of psychopathic and narcissistic personalities leads to harmful behaviors at the workplace.

First, our study highlights that public sector organizations' management must inspect the activities that became the cause of uncivil behaviors. Secondly, to overcome individuals' uncivil and unethical attitudes, public sector organizations initiate steps to test employees' personalities and psychological levels (Gulerdg, 2020; Pearson \& Porath, 2005) during the recruitment process and after recruitment on a biannual basis. Thirdly, public sector organizations conduct training sessions, seminars, and workshops on their workforce's ethical and psychological training to enhance further employees' ethical levels (Leiter et al., 2011). Finally, we suggest that the organizational leaders extend their support to build trust and cooperation among subordinates so that employees feel secure and the intensity of uncivil behavior in the workplace could be eliminated (Schilbach, Baethge, \& Rigotti, 2020).

\subsection{Future research directions and limitations}

By limitations, firstly, the present study is conducted in a Muslim state (Pakistan), so we suggest that future researchers explore another geographical context (non-Muslim). Secondly, this study is conducted with a sample of a public organization; thus, future researchers replicate this model in another public sector organizational setup. Thirdly, in the present study, we use IWVs as moderator; future researchers examine other variables such as emotional 
Chughtai, M. S., Akram, H., Razzaq, T., Rasheed, A., \& Shah, R.
Impact of Psychopathy and Narcissism on Employees' Adverse Outcomes: A Perspective of Ethical Climate Theory and Threatened-Egotism Model

intelligence, occupational calling, and mindfulness as moderator. Finally, it is suggested that future researchers also investigate the influence of leadership styles, i.e., humble leadership and spiritual leadership, on adverse outcomes, with the intervening mechanism of dark personalities.

\section{Conclusion}

The role of public sector organizations is much imperative in every state for the delivery of services to the public; for that purpose, the workforce of these organizations prerequisite holds the positive personality qualities which produce positive outcomes and public satisfaction. The present study uncovers the positive relationship between negative personality traits, i.e., psychopathy and narcissism, and employees' adverse outcomes (CWBs), especially in the context of public sector organizations in a developing economy. Moreover, the negative characteristics of these personalities (psychopathic and narcissistic) enforce the cognitively to demonstrate uncivil behaviors with others. The study's findings suggested that implementing ethical climate policies in the form of Islamic work values reduces the harmful behaviors and attitudes of the employees and enables them to reduce their adverse outcomes (CWBs).

\section{Declaration of conflicting interests}

The author(s) declared no potential conflicts of interest with respect to the research, authorship, and/or publication of this article.

\section{References}

Abbasi, A. S., Rehman, K. U., \& Bibi, A. (2011). Islamic work ethics: How it affects business performance. Actual Problems of Economics(12), 312-322.

Abbasi, T. F. (2015). Impact of Work Overload on Stress, Job Satisfaction and Turnover Intentions with Moderating Role of Islamic Work Ethics. Management Studies and Economic Systems, 54(2518), 1-11. https://doi.org/10.12816/0018080

Abid, G., Khan, B., Rafiq, Z., \& Ahmed, A. (2015). Workplace incivility: Uncivil activities, antecedents, consequences, and level of incivility. Science International, 27(6), 6307-6312.

Ahmad. (2011). Work ethics: An Islamic perspective. Journal of Human Sciences, 8(1), 850859.

Ahmed, A., Arshad, M. A., Mahmood, A., \& Akhtar, S. (2019). The influence of spiritual values on employee's helping behavior: the moderating role of Islamic work ethic.

Journal of Management, Spirituality \& Religion, 16(3), 235-263. https://doi.org/10.1080/14766086.2019.1572529

Akella, D., \& Lewis, V. J. (2019). The Modern Face of Workplace Incivility. Organization 
Management Journal, 1-6. https://doi.org/10.1080/15416518.2019.1604202

Al-Shamali, A., Irani, Z., Haffar, M., Al-Shamali, S., \& Al-Shamali, F. (2021). The influence of Islamic Work Ethic on employees' responses to change in Kuwaiti Islamic banks. $\begin{array}{lll}\text { International Business } & \text { Review, }\end{array}$ https://doi.org/10.1016/j.ibusrev.2021.101817

Andersson, L. M., \& Pearson, C. M. (1999). Tit for tat? The spiraling effect of incivility in the workplace. Academy of Management Review, 24(3), 452-471. https://doi.org/10.2307/259136

Anninos, L. N. (2018). Narcissistic business leaders as heralds of the self-proclaimed excellence. International Journal of Quality and Service Sciences, 10(1), 49-60. https://doi.org/10.1108/IJQSS-01-2017-0001

Bernard, H. R. (2017). Research methods in anthropology: Qualitative and quantitative approaches (3re (ed). ed.). Alta Mira Press. https://doi.org/10.4324/9781315248813-1

Bibi, Z., Karim, J., \& ud Din, S. (2013). Workplace incivility and counterproductive work behavior: Moderating role of emotional intelligence. Pakistan Journal of Psychological Research, 28(2), 317-334.

Boey, L., \& Vantilborgh, T. (2016). A theoretical model relating the dark triad of personality to the content of employees' psychological contracts. New Zealand Journal of Employment Relations, 40(3), 44-66.

Brender-Ilan, Y., \& Sheaffer, Z. (2019). How do self-efficacy, narcissism and autonomy mediate the link between destructive leadership and counterproductive work behaviour. Asia Pacific Management Review, 24(3), 212-222. https://doi.org/10.1016/j.apmrv.2018.05.003

Bushman, B. J., \& Baumeister, R. F. (1998). Threatened egotism, narcissism, self-esteem, and direct and displaced aggression: Does self-love or self-hate lead to violence? Journal of Personality and Social Psychology, 75(1), 219. https://doi.org/10.1037/0022-3514.75.1.219

Chaudhary, A., Islam, T., Ali, H. F., \& Jamil, S. (2021). Can paternalistic leaders enhance knowledge sharing? The roles of organizational commitment and Islamic work ethics. Global Knowledge, Memory and Communication, ahead-of-print(ahead-ofprint). https://doi.org/10.1108/GKMC-06-2021-0109

Chen, Chen, M. Y.-C., \& Liu, Y.-C. (2013). Negative affectivity and workplace deviance: The moderating role of ethical climate. The International Journal of Human Resource Management, 24(15), 2894-2910. https://doi.org/10.1080/09585192.2012.753550

Chen, \& Wang, C.-H. (2019). Incivility, satisfaction and turnover intention of tourist hotel chefs: Moderating effects of emotional intelligence. International Journal of Contemporary Hospitality Management, 31(5), 2034-2053. https://doi.org/10.1108/IJCHM-02-2018-0164

Chughtai, M., Salman., Khan, H. S. U. D., Shah, S. Z. A., \& Yusrini, L. (2020). Dark Triad, Counterproductive Work Behaviors, Workplace Incivility, and the Role of Islamic Work Values: A Moderated Mediation Model. Business Ethics and Leadership, 4(4), 55-66. https://doi.org/10.21272/bel.4(4).56-67.2020

Chughtai, M. S. (2017). Hrm Practices and Employee's Performance: Moderating Role of Islamic Work Ethics and Mediating Role of Hr Outcomes in Judiciary of Punjab, Pakistan. The Virtual University of Pakistan. 
Chughtai, M. S., Akram, H., Razzaq, T., Rasheed, A., \& Shah, R.
Impact of Psychopathy and Narcissism on Employees' Adverse Outcomes: A Perspective of Ethical Climate Theory and Threatened-Egotism Model

Chughtai, M. S., \& Ali Shah, S. Z. (2020). A Moderated Mediation Model: Mediating Mechanism of Workplace Incivility and Moderating Role of Islamic Work Ethics between Dark Triad and Organizational Citizenship Behavior. Management Issues in Healthcare System, 6(1), 1-17.

Cohen, A. (2016). Are they among us? A conceptual framework of the relationship between the dark triad personality and counterproductive work behaviors (CWBs). Human Resource Management Review, 26(1), 69-85. https://doi.org/10.1016/j.hrmr.2015.07.003

Cortina, L. M., Kabat-Farr, D., Magley, V. J., \& Nelson, K. (2017). Researching rudeness: The past, present, and future of the science of incivility. Journal of Occupational Health Psychology, 22(3), 299-313. https://doi.org/10.1037/ocp0000089

Cortina, L. M., Magley, V. J., Williams, J. H., \& Langhout, R. D. (2001). Incivility in the workplace: incidence and impact. Journal of Occupational Health Psychology, 6(1), 64-80. https://doi.org/10.1037/1076-8998.6.1.64

Cortina, L. M., Sandy Hershcovis, M., \& Clancy, K. B. (2021). The Embodiment of Insult: A Theory of Biobehavioral Response to Workplace Incivility. Journal of Management, 0149206321989798. https://doi.org/10.1177/0149206321989798

Costello, B. J., \& Dunaway, R. G. (2003). Egotism and delinquent behavior. Journal of Interpersonal Violence, 18(5), 572-590. https://doi.org/10.1177/0886260503251128

Cullen, J. B., Victor, B., \& Bronson, J. W. (1993). The ethical climate questionnaire: An assessment of its development and validity. Psychological Reports, 73(2), 667-674. https://doi.org/10.2466/pr0.1993.73.2.667

De Dreu, C. K., \& Nauta, A. (2009). Self-interest and other-orientation in organizational behavior: implications for job performance, prosocial behavior, and personal initiative. Journal of Applied Psychology, 94(4), 913-926. https://doi.org/10.1037/a0014494

Debusscher, J., Hofmans, J., \& De Fruyt, F. (2016). The effect of state core self-evaluations on task performance, organizational citizenship behaviour, and counterproductive work behaviour. European Journal of Work and Organizational Psychology, 25(2), 301-315. https://doi.org/10.1080/1359432X.2015.1063486

Eisenbarth, H., Hart, C. M., Zubielevitch, E., Keilor, T., Wilson, M., Bulbulia, J., Sibley, C. G., \& Sedikides, C. (2022). Aspects of psychopathic personality relate to lower subjective and objective professional success. Personality and Individual Differences, 186, 111340. https://doi.org/10.1016/j.paid.2021.111340

Etikan, I., Musa, S. A., \& Alkassim, R. S. (2016). Comparison of convenience sampling and purposive sampling. American journal of theoretical and applied statistics, 5(1), 14. https://doi.org/10.11648/j.ajtas.20160501.11

Garcia, D., \& Rosenberg, P. (2016). The dark cube: dark and light character profiles. PeerJ, 4, e1675. https://doi.org/10.7717/peerj.1675

Gheitani, A., Imani, S., Seyyedamiri, N., \& Foroudi, P. (2019). Mediating effect of intrinsic motivation on the relationship between Islamic work ethic, job satisfaction, and organizational commitment in banking sector. International Journal of Islamic and Middle Eastern Finance and Management, 12(1), 76-95. https://doi.org/10.1108/IMEFM-01-2018-0029

González-Navarro, P., Zurriaga-Llorens, R., Tosin Olateju, A., \& Llinares-Insa, L. I. (2018). Envy and counterproductive work behavior: The moderation role of leadership in 
public and private organizations. International journal of environmental research and public health, 15(7), 1-17. https://doi.org/10.3390/ijerph15071455

Greenbaum, R. L., Hill, A., Mawritz, M. B., \& Quade, M. J. (2017). Employee Machiavellianism to unethical behavior: The role of abusive supervision as a trait activator. Journal of Management, 43(2), 585-609. https://doi.org/10.1177/0149206314535434

Grijalva, E., \& Newman, D. A. (2015). Narcissism and counterproductive work behavior (CWB): Meta-analysis and consideration of collectivist culture, Big Five personality, and narcissism's facet structure. Applied Psychology, 64(1), 93-126. https://doi.org/10.1111/apps.12025

Gulerdg, M. (2020). The Dark Triad and Counterproductive Work Behaviors: Organizational Culture as Moderator Middle East Technical University].

Hamesch, U., Cropley, M., \& Lang, J. (2014). Emotional versus cognitive rumination: Are they differentially affecting long-term psychological health? The impact of stressors and personality in dental students. Stress and Health, 30(3), 222-231. https://doi.org/10.1002/smi.2602

Han, S., Harold, C. M., Oh, I. S., Kim, J. K., \& Agolli, A. (2021). A meta-analysis integrating 20 years of workplace incivility research: Antecedents, consequences, and boundary conditions. Journal of Organizational Behavior. 1-27. https://doi.org/10.1002/job.2568

Haque, M. S. (2002). Globalization, new political economy, and governance: A third world viewpoint. Administrative Theory \& Praxis, 24(1), 103-124. https://doi.org/10.1080/10841806.2002.11029352

Harman, D. (1967). A single factor test of common method variance. Journal of Psychology, 35(1967), 359-378.

Harms, P. D., \& Spain, S. M. (2015). Beyond the bright side: Dark personality at work. Applied Psychology, 64(1), 15-24. https://doi.org/10.1111/apps.12042

Hart, W., Adams, J. M., \& Tortoriello, G. (2017). Narcissistic responses to provocation: An examination of the rage and threatened-egotism accounts. Personality and Individual Differences, 106, 152-156. https://doi.org/10.1016/j.paid.2016.10.049

Hart, W., Tortoriello, G. K., \& Richardson, K. (2021). Provoked narcissistic aggression: Examining the role of de-escalated and escalated provocations. Journal of Interpersonal Violence, 36(9-10), 4832-4853. https://doi.org/10.1177/0886260518789901

Hauge, L. J., Skogstad, A., \& Einarsen, S. (2009). Individual and situational predictors of workplace bullying: Why do perpetrators engage in the bullying of others? Work \& Stress, 23(4), 349-358. https://doi.org/10.1080/02678370903395568

Hayati, K., Yuningsih, Y., \& Caniago, I. (2018). Can Islamic Work Ethics and Ethical Climate Reduce Counterproductive Work Behavior? International Journal of Economics, Business, and Entrepreneurship, 1(2), 95-101. https://doi.org/10.23960/ijebe.v1i2.46

Hayes, A. F. (2015). An Index and Test of Linear Moderated Mediation. Multivariate Behavioral Research, 50(1), 1-22. https://doi.org/10.1080/00273171.2014.962683

Hayes, A. F. (2018). Introduction to Mediation, Moderation, and Conditional Process Analysis (Second Edition ed.). The Guilford Press.

He, Y., Walker, J. M., Payne, S. C., \& Miner, K. N. (2021). Explaining the negative impact of workplace incivility on work and non-work outcomes: The roles of negative 
Chughtai, M. S., Akram, H., Razzaq, T., Rasheed, A., \& Shah, R.
Impact of Psychopathy and Narcissism on Employees' Adverse Outcomes: A Perspective of Ethical Climate Theory and Threatened-Egotism Model

rumination and organizational support. Stress and Health, 37(2), 297-309. https://doi.org/10.1002/smi.2988

Islam, T., Ahmed, I., Usman, A., \& Ali, M. (2021). Abusive supervision and knowledge hiding: the moderating roles of future orientation and Islamic work ethics. Management Research Review, 44(12), 1565-1582.

Jakobwitz, S., \& Egan, V. (2006). The dark triad and normal personality traits. Personality and Individual Differences, 40(2), 331-339. https://doi.org/10.1016/j.paid.2005.07.006

Javaid, M., Abdullah, N., Zeb, A., \& Hussain, K. (2018). The Impact of Authentic Leadership on Knowledge Sharing Behavior with the Moderating role of Islamic Work Ethics. Journal of Physics: Conference Series, 1049, 012007 https://doi.org/10.1088/17426596/1049/1/012007

Jelavić, S. R., Aleksić, A., \& Braje, I. N. (2021). Behind the Curtain: Workplace IncivilityIndividual Actors in Cultural Settings. Sustainability, 13(3), 1249. https://doi.org/10.3390/su13031249

Jonason, P. K., Wee, S., \& Li, N. P. (2015). Competition, autonomy, and prestige: Mechanisms through which the Dark Triad predict job satisfaction. Personality and Individual Differences, 72, 112-116. https://doi.org/10.1016/j.paid.2014.08.026

Jones, \& Paulhus. (2014). Introducing the short dark triad (SD3) a brief measure of dark personality traits. Assessment, 21(1), 28-41. https://doi.org/10.1177/1073191113514105

Kareem, O., \& bin Azmin, A. A. (2018). The Influence of Islamic Work Ethics on the Magnitude of Organizational Culture's Effect on SME Performance in Nigeria: A Conceptual Framework. International Journal of Academic Research in Business and Social Sciences, 8(4), 11-23. https://doi.org/10.6007/IJARBSS/v8-i4/3994

Karim, J., Bibi, Z., Rehman, S. U., \& Khan, M. S. (2015). Emotional intelligence and perceived work-related outcomes: Mediating role of workplace incivility victimization. Pakistan Journal of Psychological Research, 30(1), 21-37.

Konrath, S., Bushman, B. J., \& Campbell, W. K. (2006). Attenuating the link between threatened egotism and aggression. Psychological Science, 17(11), 995-1001. https://doi.org/10.1111/j.1467-9280.2006.01818.x

Kozako, Anual, N., Karim, Z. H. A., Shamsuddin, N., \& Mustafa, Z. (2018). The Islamic Views on Counterproductive Work Behavior: Islamic Work Ethics Perspectives. Conference: International Conference On Islam And Global Issues, Universiti Teknologi MARA Cawangan Kelantan.

Lata, M., \& Chaudhary, R. (2020). Dark Triad and instigated incivility: The moderating role of workplace spirituality. Personality and Individual Differences, 166, 110090. https://doi.org/10.1016/j.paid.2020.110090

LeBreton, J. M., Shiverdecker, L. K., \& Grimaldi, E. M. (2018). The dark triad and workplace behavior. Annual Review of Organizational Psychology and Organizational Behavior, 5, 387-414. https://doi.org/10.1146/annurev-orgpsych-032117-104451

Leiter, M. P., Laschinger, H. K. S., Day, A., \& Oore, D. G. (2011). The impact of civility interventions on employee social behavior, distress, and attitudes. Journal of Applied Psychology, 96(6), 1258-1274. https://doi.org/10.1037/a0024442

Lim, S., \& Cortina, L. M. (2005). Interpersonal mistreatment in the workplace: the interface and impact of general incivility and sexual harassment. Journal of Applied Psychology, 90(3), 483-496. https://doi.org/10.1037/0021-9010.90.3.483 
Lim, S., Cortina, L. M., \& Magley, V. J. (2008). Personal and workgroup incivility: Impact on work and health outcomes. Journal of Applied Psychology, 93(1), 95-107. https://doi.org/10.1037/0021-9010.93.1.95

Liu, P., Xiao, C., He, J., Wang, X., \& Li, A. (2020a). Experienced workplace incivility, anger, guilt, and family satisfaction: The double-edged effect of narcissism. Personality $\begin{array}{llll}\text { and Individual } & \text { Differences, }\end{array}$ https://doi.org/10.1016/j.paid.2019.109642

Liu, P., Xiao, C., He, J., Wang, X., \& Li, A. (2020b). Experienced workplace incivility, anger, guilt, and family satisfaction: The double-edged effect of narcissism. Personality and Individual Differences, 154, 1-7.

Loh, J. M., Thorsteinsson, E. B., \& Loi, N. M. (2021). Workplace incivility and work outcomes: Cross-cultural comparison between Australian and Singaporean employees. Asia Pacific Journal of Human Resources, 59(2), 305-329. https://doi.org/10.1111/1744-7941.12233

Martin, K. D., \& Cullen, J. B. (2006). Continuities and extensions of ethical climate theory: A meta-analytic review. Journal of Business Ethics, 69(2), 175-194. https://doi.org/10.1007/s10551-006-9084-7

McShane, S. L., \& Von Glinow, M. A. (2013). Organizational Behavior 5/e. Pearson Publication Inc.

Miller, J. D., Back, M. D., Lynam, D. R., \& Wright, A. G. (2021). Narcissism today: What we know and what we need to learn. Current Directions in Psychological Science, 30(6), 519-525. https://doi.org/10.1177/09637214211044109

Morf, \& Rhodewalt. (2001). Unraveling the paradoxes of narcissism: A dynamic selfregulatory processing model. Psychological Inquiry, 12(4), 177-196. https://doi.org/10.1207/S15327965PLI1204_1

Murtaza, G., Abbas, M., Raja, U., Roques, O., Khalid, A., \& Mushtaq, R. (2016). Impact of Islamic Work Ethics on Organizational Citizenship Behaviors and KnowledgeSharing Behaviors. Journal of Business Ethics, 133(2), 325-333. https://doi.org/10.1007/s10551-014-2396-0

Murtaza, G., Roques, O., \& Khan, R. (2020). Religious beliefs as a moderator of the relationships between workplace incivility and counterproductive work behaviours. Human Systems Management(Preprint), 1-11.

Nasution, F. N., \& Rafiki, A. (2019). Islamic work ethics, organizational commitment and job satisfaction of Islamic banks in Indonesia. RAUSP Management Journal, 55(2), 195-205. https://doi.org/10.1108/RAUSP-01-2019-0011

O'Boyle, E. H., Forsyth, D. R., Banks, G. C., \& McDaniel, M. A. (2012). A meta-analysis of the Dark Triad and work behavior: a social exchange perspective. Journal of Applied Psychology, 97(3), 557-579. https://doi.org/10.1037/a0025679

Özsoy, E. (2018). Dark Triad and Counterproductive Work Behaviors: Which of the Dark Triad Traits is More Malevolent? Işletme Araştırmalarl Dergisi, 10(4), 742-756. https://doi.org/10.20491/isarder.2018.546

Pagliaro, S., Lo Presti, A., Barattucci, M., Giannella, V. A., \& Barreto, M. (2018). On the effects of ethical climate (s) on employees' behavior: a social identity approach. Frontiers in Psychology, 9, 1-10. https://doi.org/10.3389/fpsyg.2018.00960

Paulhus, D. L., \& Williams, K. M. (2002). The dark triad of personality: Narcissism, Machiavellianism, and psychopathy. Journal of research in personality, 36(6), 556563. https://doi.org/10.1016/S0092-6566(02)00505-6 
Chughtai, M. S., Akram, H., Razzaq, T., Rasheed, A., \& Shah, R.
Impact of Psychopathy and Narcissism on Employees' Adverse Outcomes: A Perspective of Ethical Climate Theory and Threatened-Egotism Model

Pearson, C. M., \& Porath, C. L. (2005). On the nature, consequences and remedies of workplace incivility: No time for "nice"? Think again. Academy of Management Perspectives, 19(1), 7-18. https://doi.org/10.5465/ame.2005.15841946

Penney, L. M., \& Spector, P. E. (2005). Job stress, incivility, and counterproductive work behavior (CWB): The moderating role of negative affectivity. Journal of Organizational Behavior: The International Journal of Industrial, Occupational and Organizational Psychology and Behavior, 26(7), 777-796. https://doi.org/10.1002/job.336

Phipps, S. T., Prieto, L. C., \& Deis, M. H. (2015). The role of personality in organizational citizenship behavior: Introducing counterproductive work behavior and integrating impression management as a moderating factor. Journal of Organizational Culture, Communications and Conflict, 19(1), 176-196.

Porath, \& Erez, A. (2009). Overlooked but not untouched: How rudeness reduces onlookers' performance on routine and creative tasks. Organizational Behavior and Human Decision Processes, 109(1), 29-44. https://doi.org/10.1016/j.obhdp.2009.01.003

Porath, \& Pearson, C. (2013). The price of incivility. Harvard Business Review, 91(1-2), 115121.

Qayyum, A., Kousar, S., Jamil, R. A., \& Sarmad, M. (2018). Relationship between WorkFamily and Interpersonal Conflicts: Mediating Role of Psychological Distress and the Moderating Effect of Islamic Work Ethics. Journal of Islamic Business and Management, 8(2), 501-519. https://doi.org/10.26501/jibm/2018.0802-010

Quoquab, F., \& Mohammad, J. (2013). Work ethics from the viewpoint of different religious faiths: do they talk the same? Journal of Applied Sciences Research, 9(9), 54365452.

Rice, G. (1999). Islamic ethics and the implications for business. Journal of Business Ethics, 18(4), 345-358. https://doi.org/10.1023/A:1005711414306

Rizk, R. R. (2008). Back to basics: an Islamic perspective on business and work ethics. Social Responsibility

Journal, $4(1 / 2)$,

246-254. https://doi.org/10.1108/17471110810856992

Roeser, K., McGregor, V. E., Stegmaier, S., Mathew, J., Kübler, A., \& Meule, A. (2016). The Dark Triad of personality and unethical behavior at different times of day. Personality and Individual Differences, 88, 73-77. https://doi.org/10.1016/j.paid.2015.09.002

Schilbach, M., Baethge, A., \& Rigotti, T. (2020). Why employee psychopathy leads to counterproductive workplace behaviours: an analysis of the underlying mechanisms. European Journal of Work and Organizational Psychology, 1-14. https://doi.org/10.1080/1359432X.2020.1739650

Schilpzand, P., De Pater, I. E., \& Erez, A. (2016). Workplace incivility: A review of the literature and agenda for future research. Journal of Organizational Behavior, 37, S57-S88. https://doi.org/10.1002/job.1976

Sguera, F., Bagozzi, R. P., Huy, Q. N., Boss, R. W., \& Boss, D. S. (2016). Curtailing the harmful effects of workplace incivility: The role of structural demands and organization-provided resources. Journal of Vocational Behavior, 95, 115-127. https://doi.org/10.1016/j.jvb.2016.08.004

Shagufta, S., \& Nazir, S. (2021). Self-esteem and psychopathic traits among undergraduate students: A Structural Equation Modelling Approach. FWU Journal of Social Sciences, 15(2), 117-131. https://doi.org/10.51709/19951272/Summer-2/7 
Shin, Y., \& Hur, W.-M. (2019). Supervisor incivility and employee job performance: The Mediating roles of job insecurity and amotivation. The Journal of Psychology, 154(1), 38-59. https://doi.org/10.1080/00223980.2019.1645634

Spector, P. E. (2011). The relationship of personality to counterproductive work behavior (CWB): An integration of perspectives. Human Resource Management Review, 21(4), 342-352. https://doi.org/10.1016/j.hrmr.2010.10.002

Spector, P. E., Fox, S., Penney, L. M., Bruursema, K., Goh, A., \& Kessler, S. (2006). The dimensionality of counterproductivity: Are all counterproductive behaviors created equal? Journal of Vocational Behavior, 68(3), 446-460. https://doi.org/10.1016/j.jvb.2005.10.005

Stenason, L. (2014). Implicit and Explicit self-esteem in relation to the Dark Triad. Western Undergraduate Psychology Journal, 2(1), 1-15.

Stoica, A. A. (2021). Dark Triad, Risk Taking and Counterproductive Work Behavior in Different Organizational Contexts. Studia Doctoralia, 12(1), 4-19. https://doi.org/10.47040/sd/sdpsych.v12i1.120

Suib, F. H., \& Said, M. F. (2017). A review of Islamic work ethics and spirituality concepts in service industry. Journal of Nusantara Studies (JONUS), 2(2), 282-294. https://doi.org/10.24200/jonus.vol2iss2pp282-294

Suryanto, T. (2016). Islamic work ethics and audit opinions: Audit professionalism and dysfunctional behavior as intervening variables. Al-Iqtishad: Jurnal Ilmu Ekonomi Syariah, 8(1), 49-64. https://doi.org/10.15408/aiq.v8i1.2508

Vickers, M. H. (2006). Writing what's relevant: Workplace incivility in public administration-A wolf in sheep's clothing. Administrative Theory \& Praxis, 28(1), 69-88. https://doi.org/10.1080/10841806.2006.11029525

Victor, B., \& Cullen, J. B. (1987). A theory and measure of ethical climate in organizations. Research in corporate social performance and policy, 9(1), 51-71.

Victor, B., \& Cullen, J. B. (1988). The organizational bases of ethical work climates. Administrative Science Quarterly, 101-125. https://doi.org/10.2307/2392857

Viswesvaran, C., Deshpande, S. P., \& Milman, C. (1998). The effect of corporate social responsibility on employee counterproductive behavior. Cross Cultural Management: An International Journal, 5(4), 5-12. https://doi.org/10.1108/13527609810796835

Vize, C. E., Miller, J. D., Collison, K. L., \& Lynam, D. R. (2021). Untangling the relation between narcissistic traits and behavioral aggression following provocation using an FFM framework. Journal of personality disorders, 35(2), 299-318. https://doi.org/10.1521/pedi_2020_34_321

Wahab, M. A., Quazi, A., \& Blackman, D. (2016). Measuring and validating Islamic work value constructs: An empirical exploration using Malaysian samples. Journal of Business Research, 69(10), 4194-4204. https://doi.org/10.1016/j.jbusres.2016.03.005

Wang, Y.-D., \& Hsieh, H.-H. (2013). Organizational ethical climate, perceived organizational support, and employee silence: A cross-level investigation. Human Relations, 66(6), 783-802. https://doi.org/10.1177/0018726712460706

Wilson, J. A. (2012). The new wave of transformational Islamic marketing. Journal of Islamic Marketing, 3(1), 5-11. https://doi.org/10.1108/17590831211225436

Yang, F.-H., Tsai, Y.-S., \& Tsai, K.-C. (2014). The Influences of Ethical Climate of Turnover Intention: The mediation role of Emotional Exhaustion. International Journal of 
Chughtai, M. S., Akram, H., Razzaq, T., Rasheed, A., \& Shah, R.
Impact of Psychopathy and Narcissism on Employees' Adverse Outcomes: A Perspective of Ethical Climate Theory and Threatened-Egotism Model

Organizational Innovation, 6(4), 72-89.

Yousef, D. A. (2001). Islamic work ethic - A moderator between organizational commitment and job satisfaction in a cross-cultural context. Personnel Review, 30(2), 152-169. https://doi.org/10.1108/00483480110380325

Yuliusdharma, Y., Likdanawati, L., Khalsiah, K., \& Wafi, A. (2022). Work Islamic Ethics, Organizational Culture, Work Motivation on Citizenship Organization Behavior and Employees Performance at Bank Aceh Sharia. Budapest International Research and Critics Institute (BIRCI-Journal): Humanities and Social Sciences, 5(1), 11261133. 